\title{
Sonic hedgehog signaling in epithelial tissue development
}

\author{
Lu Zheng, Chen Rui, Hao Zhang, Jing Chen, Xiuzhi Jia*, and Ying Xiao
}

Central Lab of Biomedical Research Center, Sir Run Run Shaw Hospital, School of Medicine, Zhejiang University, Hangzhou, PR China

Received 9 November 2019, Accepted 9 December 2019, Published online 31 December 2019

\begin{abstract}
The Sonic hedgehog (SHH) signaling pathway is essential for embryonic development and tissue regeneration. The dysfunction of SHH pathway is involved in a variety of diseases, including cancer, birth defects, and other diseases. Here we reviewed recent studies on main molecules involved in the SHH signaling pathway, specifically focused on their function in epithelial tissue and appendages development, including epidermis, touch dome, hair, sebaceous gland, mammary gland, tooth, nail, gastric epithelium, and intestinal epithelium. The advance in understanding the SHH signaling pathway will give us more clues to the mechanisms of tissue repair and regeneration, as well as the development of new treatment for diseases related to dysregulation of SHH signaling pathway.
\end{abstract}

Keywords: Sonic hedgehog, epidermis, skin appendages, mammary gland, gastric epithelium, intestinal epithelium

\section{Introduction}

\subsection{SHH signaling pathway}

In the development of invertebrates and vertebrates, the members of the hedgehog $(\mathrm{HH})$ signaling family mediate many essential processes, including short-term and long-term modeling. The $H h$ gene family encodes a secreted protein that plays a critical regulatory role in the process of embryogenesis and environmental stabilization in adult tissues of invertebrates and vertebrates [44]. In the fly, signals are regulated by a single $H h$ gene, while in mammals, Sonic (SHH), Indian (IHH), and Desert (DHH) hedgehog play different regulatory roles $[37,148]$.

The SHH pathway should be off at most of the time, by the inhibition of specific factors such as Patched 1 (PTC1), Protein Kinase A (PKA), Casein Kinase1 (CK1), and Glycogen Synthase Kinase 3 beta (GSK3b), and only valid at precise time points [98]. It plays a biological role by terminating the factor of glioma-associated oncogene $(\mathrm{Gli})$ [144]. In this way, SHH mediates various reactions by the regulation between activator form and repressor form. IHH is a core factor in the morphogenesis of vertebrate skeleton. IHH signal induces activation of Parathyroid Hormone-related Protein (PTHRP) on the articular surface and gets rid of the hypertrophy of chondrocytes [49]. It also participates in endochondral bone formation as a negative regulator of chondrocyte differentiation in mouse [131] and is involved in the development of

\footnotetext{
*Corresponding author: xiaoying.srr@zju.edu.cn; also correspond to jiaxiuzhi@zju.edu.cn
}

gastrointestinal tract [127] and mammary glands [56]. Meanwhile, DHH plays a vital role in $\mathrm{HH}$ signaling. $\mathrm{DHH}$ PTC1 signaling triggers differentiation of Leydig cells by up-regulating Steroidogenic Factor 1 and expression of cytochrome P450 Side-Chain Cleavage enzyme located outside testicular cord [145].

$\mathrm{HH}$ ligands are tissue-specific expressed, but may also be co-expressed in the same tissue. For example, $S h h, D h h$, and $I h h$ are specifically expressed in the adrenal, testis, and endochondral bones, respectively [61], whereas both of $\mathrm{SHH}$ and $\mathrm{IHH}$ are detected in organs such as embryonic heart [148], gut [11], bladder [39], prostate [59] and stomach [89]. The interactions of the three $\mathrm{HH}$ factors are complicated. In the adrenal gland, $\mathrm{SHH}$ and $\mathrm{DHH}$ act synergistically [114]; In the Dhh-mutant epididymis, SHH plays a compensatory role in order to maintain the stability of the signaling pathway [21].

\subsection{Molecules and their functions in the $\mathrm{SHH}$ signaling pathway}

The conduction of SHH signaling pathway requires the participation of many proteins and factors (Tab. 1), mainly including SHH, PTC receptors (PTC1, PTC2), Smoothened receptor (SMO), Kinesin Family member7 (KIF7), Suppressor of fused homolog (SUFU), PKA, and GLI transcription factors (GLI1, GLI2, GLI3) [130] (Fig. 1). In the absence of SHH, PTC and G Proteincoupled Receptor161 (GPR161) are located at the base of primary cilium (PC), while accumulation of SMO is diminished by transporting sterol-like SMO ligand outside 

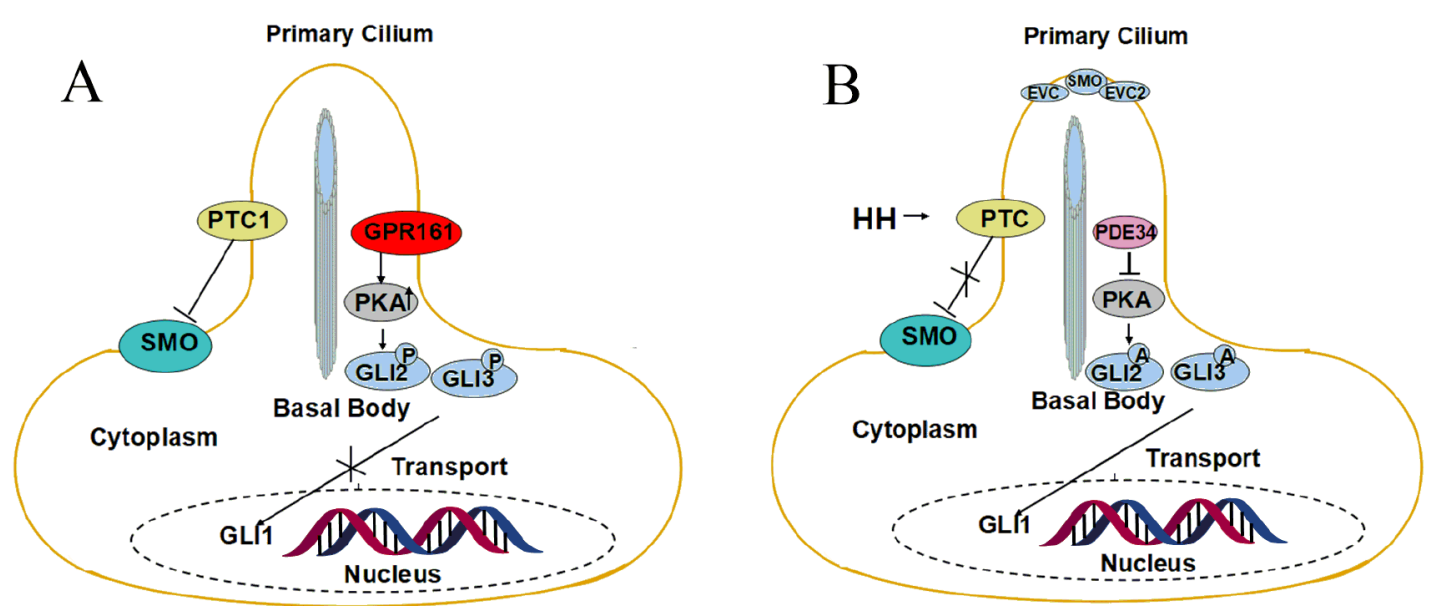

Fig. 1. HH signaling pathway in the primary cilium. In the absence of SHH, PTC1 is located at PC, indirectly inhibiting accumulation of SMO by transporting putative sterol ligand outside with a 'tunnel' structure. Meanwhile, PKA is up-regulated by GPR161, located at the base of PC, through increasing cAMP level. GLI2 and GLI3 are then phosphorylated by PKA, CK1, GSK3b, and sequestered by SUFU. Phosphorylated GLI2 and GLI3 are easy to get cleaved and repress the GLI-dependent transcription of target genes. In the presence of SHH ligand, the inhibit of SMO declined by the interaction between SHH and PTC1. SMO forms a complex with EVC and EVC2, and transports into PC structure. Level of cAMP is then down-regulated, preventing GLI2 and GLI3 from being phosphorylated. Full-length GLI2 and GLI3 actives GLI1 to translocate to the nucleus and induces the expression of HH target genes.

Table 1. HH pathway modulators.

\begin{tabular}{llll}
\hline $\begin{array}{l}\text { Factor } \\
\text { effected }\end{array}$ & Functions & Modulators & $\begin{array}{l}\text { References } \\
\text { (PMID) }\end{array}$ \\
\hline HH & Antagonist & RU-SKI 39 & {$[81]$} \\
& & RU-SKI41 & \\
& RU-SKI43 & \\
SHH & Block & RE-SKI 50 & {$[26]$} \\
PC & Antagonist & CA1 & {$[142]$} \\
& Antagonist & DHCEO & {$[101]$} \\
SMO & & SMANT & {$[137]$} \\
& & KAAD-cyclopamine, & {$[113]$} \\
& & Jervine & {$[12]$} \\
& & Saridegib & {$[123]$} \\
& & Vitamin D & {$[10]$} \\
& & SEN450 & {$[29]$} \\
SMO & Agonist & SAG & {$[30]$} \\
& & Purmorphamine, & {$[105]$} \\
& & Oxysterols & {$[69]$} \\
& & Cholesterol, & {$[63]$} \\
& & PI4P & {$[47]$} \\
& & GSA-10 & {$[33]$} \\
GLI & Antagonist & Arsenic trioxide & {$[7]$} \\
\hline
\end{tabular}

by a 'tunnel' structure of PTC1. GLI2 and GLI3 are phosphorylated by PKA, CK1, and GSK3b, which are sequestered by SUFU. Herein, GPR161 acts as an activator of PKA, which is up-regulated by Adenosine Cyclophosphate (cAMP) in PC structure. Phosphorylated GLI2 and GLI3 are processed into repressor forms by the proteasome and repress the GLI-dependent transcription of target genes. In the presence of $\mathrm{SHH}$, PTC1 and GPR161 are transferred out of PC upon binding with $\mathrm{SHH}$, declining the inhibition of SMO, and activating its movement into PC. SMO forms a sophisticated structure with EVC and EVC2 to proceed signal transduction of $\mathrm{HH}$ pathway. Activated SMO reduces the suppression of GLI2 and GLI3 mediated by SUFU. The exit of GPR161 from PC weakens the level of cAMP and PKA, which can help GLI2 and GLI3 to maintain their full-length forms without being phosphorylated and active GLI1. Finally, the activated form of GLI1 translocates into the nucleus and induces the expression of HH target genes [141].

\subsubsection{PC}

Cilia are microtubule organelles that exist in most eukaryotic cells, and they can be classified as inactive (Primary Cilia, PC) or active cilia. During SHH signaling in vertebrates, the primary cilium acts as a signaling antenna by preferentially localizing selected components [76]. Nearly all kinds of interphase vertebrate cells possess a primary cilium structure that extends into the extracellular environment to work as mechanical models and mechanical sensors [22], which is also crucial in determining the left-right axis asymmetry of the process development [85]. Although the motile cilia produce extracellular fluid flow or drive a single cell, the primary cilia have long been considered to be remaining [8]. The cilia and flagella contain the axoneme with 9 peripheral microtubule cores. In the active cilia, these diploids are surrounded by a pair of central microtubules, which can be called " $9+2$ " superstructure while the lack of central pair can make the primary cilium axoneme as " $9+0$ " arrangement [23].

The primary cilium is essential for regular anterior segment (AS) development during eye embryogenesis, and primary cilium defects may lead to diseases like congenital 
glaucoma. Recent evidence suggests a unique structure composed of lipid membrane, a key role for cilia function and $\mathrm{HH}$ signaling, demonstrating a link between cilia regulation of phosphoinositides by inositol polyphosphate 5-phosphatase (INPP5E) and SHH regulation via ciliary trafficking of Tubby-like protein 3 (TULP3)/GPR161, and also provide mechanistic vision into ciliary alterations found in Serge N. Schiffmann syndromes resulting from INPP5E mutations [17]. Ras genes of rat brain-35 (RAB35) regulate the transport pathways necessary for the formation, function, and composition of primary cilia in mammalian cells and zebrafish.

\subsection{2 $\mathrm{SHH}$}

A vertebrate gene, which is homologous to the Drosophila segmental polarity gene, was cloned and named Shh in 1993. SHH is a protein secreted from the zone of polarizing activity (ZPA) with a tetrahedrally coordinated $\mathrm{Zn}^{2+}$ cation and $\mathrm{Ca}^{2+}$ cation, and acts as a morphogenetic factor, spreading in a gradient from back to front in the whole limb field. It acts as a ligand for membrane-bound receptors (such as PTC) rather than as an active protease [31]. SHH is a $45 \mathrm{kDa}$ precursor protein, and full-length $\mathrm{SHH}$ protein has no activity in binding with PTC1 [100]. During the biosynthetic process, SHH precursors are autocatalyzed on the endoplasmic reticulum to release an amino-terminal signal domain (SHH-N), whose carboxyl-terminal is covalently bound to cholesterol. SHH acyltransferase then adds palmitate $\alpha$-amino group of amino specific cysteine to produce mature doublelipidated signal molecule [83]. It has already known that cholesterol is a lipophilic part, covalently connected to the amino-terminal signaling domain during its processing, with the carboxyl-terminal as an intramolecular structure [84]. The N- and C-modifications are necessary for producing founctional $\mathrm{SHH}$, the mechanism can be described as follows : (1) SHH-N with aliphatic acylation is more active than unacylated $\mathrm{SHH}-\mathrm{N}$, as determined by differentiation analysis and $\mathrm{HH}$ signaling analysis; (2) blocking HH-N palmitoglycation (by mutation of its palmitoglycation site) affects embryonic development in Mice and Drosophila; HH acyltransferase inhibitors prevent $\mathrm{SHH}$ from getting palmitoylated also blocks $\mathrm{HH}$ signaling.

The other fragment is $25 \mathrm{kDa}$ C-terminal fragment with automatic processing mechanism activity [35,97]. Traci M. Tanaka Hall et al. identified a $17 \mathrm{kDa}$ fragment of $\mathrm{HH}-\mathrm{C}(\mathrm{HH}-\mathrm{C} 17)$ that plays a role in initiating automatic processing and reported its crystal structure, leading to intramolecular cleavage of the full-length $\mathrm{HH}$ protein and partial covalent attachment of cholesterol to the newly formed amino-terminal fragment [35].

Fan jiajun et al. have reported that vismodegib, an inhibitor of SHH pathway, had only a slight anti-tumor effect on A549 and NCI-H1975 lung adenocarcinoma cells, with Gli2 overexpressed and autophagy activity increased [27]. The deformities associated with Shh gene mutations highlight the importance of SHH in embryonic development [95]. Shh knockout mice have developmental defects that eventually lead to their embryonal lethal phenotype.

\subsubsection{PTC}

All initiation signaling of the SHH pathway is started by binding to its receptor, PTC receptors (PTC1 and PTC2) [96]. Both PTC receptors have been shown to exhibit $\mathrm{HH}$ ligand-binding activity with similar affinity and form a complex with SMO, while concomitant loss of PTC1 and PTC2 activity inhibits epidermal differentiation.

Compared with PTC2, the function of the mammalian PTC1 paralogue is quite clear. Human PTC1 consists of 1,447 amino acids, including three approximately $30-\mathrm{kD}$ soluble domains, 12 transmembrane helices, and two extracellular domains (ECD-I and ECD-II), whose function is to bind HH-N and one cytoplasmic carboxylterminal domain (CTD). Besides, transmembrane helices 2-6 (TM2-TM6) of PTC are predicted to form a sterolsensing domain (SSD), which is involved in cholesterol metabolism and signaling in other proteins such as Niemann-Pick C1 (NPC1) and 3-hydroxy-3-methylglutaryl coenzyme-A (HMG-CoA) reductase [32]. Xiaofeng Qi et al. discovers that the structure of PTC1 has internal two-fold pseudo-symmetry in the transmembrane core, which features two homologous extracellular domains and a sterol-sensing domain [86].

There are 3 endogenous sterol-like densities in the PTC1 protein: the first in the extracellular domain I, the second in the sterol-sensing domain, and the last in the $\mathrm{N}$ terminus of TM [87]. The interactions between $\mathrm{SHH}$ and PTC was confirmed by R. Blake Pepinsky, who constructed mutants of 11 selected amino acid residues around the surface of SHH into cysteine residues using mapping strategy. Regardless of the attachment size, about one-third of the SHH surface can be modified without affecting the function, and Asn-50 and Ser-156 sites are very close to PTC binding sites [79].

Unliganded PTC inhibits $\mathrm{SHH}$ signaling, and this repression could be released when $\mathrm{HH}$ binds to PTC. Early in 1998, Chen et al. ensured that PTC usually binds to $\mathrm{SHH}$ without the help of SMO [18]. Specifically, after $\mathrm{HH}$ binding, PTC releases its repression of SMO. A recent structure study suggests that $\mathrm{HH}$ binding may be close to an inside 'tunnel' structure in PTC1, which transport sterol ligand to accumulate on the membrane for SMO, and then SMO activates GLI proteins, which transcripts $\mathrm{HH}$ target genes that promote cell proliferation and differentiation activation [86].

The PTC1 ciliary intensity is regulated by truncating PTC cytoplasmic tail length, leading to highly correlated SMO inhibition, which strongly indicates the critical role of ciliary PTC1 in inhibiting SMO activity [50]. Inhibition of PTC1 in vertebrates is caused by direct binding with N-terminal of palmitoylated $\mathrm{SHH}$, which is sufficient enough to inhibit PTC1 and activate signal transduction [124]. 


\subsubsection{HHIP}

HHIP is a surface receptor antagonist that is equally effective against all three mammalian $\mathrm{HH}$ homologs, which was identified and named in 1999 by Chuang and McMahon [21]. Computational analysis of the HHIP ECD sequence suggested the presence of four distinct globular domains: a cysteine-rich N-terminal domain with a Frizzled $(\mathrm{Fz})$ fold, a central six-bladed $\beta$-propeller, and two C-terminal epidermal growth factor (EGF) repeats. HHIP competes for SHH binding to PTC1 and has a stronger affinity than PTC1. HHIP and PTC1 both bind at the SHH pseudo active site groove with $\mathrm{Zn}^{2+}$ cation competitively. The study of HHIP- and PTC1-peptide binding suggest a 'patch for Patched' at the SHH pseudo active site [13]

\subsubsection{GPR161}

GPR161 is a PKA substrate and also has an A-Kinase Anchoring Protein (AKAP) motif embedded in its Cterminal tail and creates a cAMP-sensing signalosome. In addition, GPR161 is effective in recruiting isoform-specific PKA complexes to primary cilia. Mukhopadhyay, et al. identify the cilium-localized orphan GPR161 to be a negative regulator of SHH signaling during development of neural tube [68]. Gpr161 is a tumor suppressor gene of SHH subtype medulloblastoma (MB). The deletion of GPR161 increases the downstream activity of $\mathrm{SHH}$ pathway by downregulating GLI3-mediated inhibition. It is further found that early deletion of Gpr161 during embryogenesis increases the incidence and severity of tumors [103].

\subsubsection{SMO}

SMO protein is a key signal transducer in the $\mathrm{HH}$ signaling pathway, responsible for maintaining normal embryonic development and participating in carcinogenesis [133].

SMO belongs to the F-class of the G-protein-coupled receptor (GPCR) superfamily and is characterized by extracellular cysteine-rich domain (CRD), followed by extracellular linker domain (LD) that connect the 7-TM domain. Similar to the classical GPCRs, it has been proposed that the output of SMO is controlled by a balance of active and inactive conformations, regulated by small molecular ligands [112]. Recently, cholesterol is identified as the endogenous SMO agonist [43]. Nachtergaele et al. present the $2.3 \AA$ crystal structure of vertebrate SMO with the extracellular cysteine-rich domain [70]. CRD is a crucial regulatory module of SMO activation and is necessary to respond to the signal transduction of natural $\mathrm{HH}$ ligand. The secreted amino-terminal domain seems to be responsible for signal transduction activity, while the carboxyl-terminal domain contains self-processing activity. It has been reported that the domain may act an essential role in hydrolase by analyzing the crystal structure of SHH amino-terminal domain [36]. Previous structural studies have shown that SMO CRD can bind to sterol-like ligands to regulate SMO activity [63]. SMO contains a ligand-binding pocket in its 7-TM region that can bind ligands and act as agonist or antagonist [134]. Qi et al. demonstrate that 24,25-epoxycholesterol can function as an endogenous ligand of PTC1, which can stimulate $\mathrm{HH}$ signaling in cells and can trigger G-protein signaling via human SMO in vitro [88].

\subsubsection{SUFU}

In the absence of SHH, SUFU makes the regulation of truncating GLI2 and GLI3. Meanwhile, it releases fulllength GLI in the cytoplasm, protecting a pool of potential proteins that can be converted to be activators or repressors as needed. This character makes SUFU at the center factor of the pathway and a key regulator of all GLI factors. Activation of the pathway promotes the dissociation of the SUFU-GLI complex and the nuclear translocation of GLI protein $[117,149]$. SUFU also interacts with GLI2 in the nucleus to inhibit GLI2 activity [38], cooccupies HH target gene promoter with GLI protein, p66 $\beta$, a chromatin-remodeling factor, and myelocytomatosis binding protein (MYCBP), a transcriptional regulatory factor [38].

\subsubsection{KIF7}

KIF7 is a mammal homologous to Drosophila Costal2 (Cos2), has the function of regulating signal transmission from SMO to GLI. The accumulation of KIF7 in the primary cilia is regulated by $\mathrm{HH}$ [25]. Human KIF contains an N-terminal kinematic domain, consisted of a nucleotide-binding region an microtubule (MT) interaction region, followed by a responsible oligomeric helix and a C-terminal globular tail domain [52]. Without stimulation, KIF7 locates at the base of primary cilia, thus prevent GLI2 and GLI3 accumulation. KIF7 mutant is effective to deregulation of GLI transcription process of target genes [58].

\subsubsection{GLI}

The mammalian counterpart of Drosophila Ci is GLI transcription factors. GLI factors are zinc finger Gliomaassociated transcription factors, which mediate the transcription of $\mathrm{HH}$ target genes. There are three GLI homologies in mammals, GLI2 and GLI3 are bifunctional transcription factors with both activation (C-terminal) and inhibition (N-terminal) domains, which can be both as activators or repressors in the signaling pathway. Due to the lack of N-terminal inhibitory domain, GLI1 can only act as a transcriptional activator, regulated by phosphorylation/maintenance of the full length of GLI2 and GLI3 [45].

The activation of GLI transcription factors in the nucleus promotes the transcription of various target genes, including those involved in $\mathrm{SHH}$ pathway feedback, such as PTC1, proliferation promoting genes, cell cycle 
regulators, and apoptosis regulators [73]. The results of this pathway depend on the balance between the activation and inhibition of GLI protein. Research in 2019 has found that the maximum activation of GLI1 is dependent on cilia, but in the absence of cilia, there is partial activation of GLI1 by HH signal mediated by SMO [136].

In the absence of HH ligands, GLI3 is the central inhibitor of this pathway, while in their presence, GLI2 is the main HH effector for Gli1 expression [15]. SHH inhibits the proteolysis of full-length GLI3, remains the untruncated form of GLI3 and promotes the activity of full-length GLI1, 2 and 3 activators [60,132]. Recent studies have found that $\mathrm{SHH} / \mathrm{GLI} 2$ and $\mathrm{SHH} / \mathrm{GLI} 3$ signals are necessary for the healthy development of mouse placentas, and may be important factors for pregnant maintenance [77].

\subsubsection{Other molecules}

The regulation of PTC1 on HH signal on cell surface is finely controlled by many other cell surface molecules, such as the invertebrate proteins interference hedgehog (IHOG) [64], brother of IHOG (BOI) [146], their corresponding vertebrate homologs (CDON) [147] and brother of CDON (BOC) [119]. Although CDON and IHOG are similar in function, IHOG binds to a different surface near the second $\mathrm{HH}$ helix, and this interaction requires heparin, which not only connects two binding partners, but also promotes IHOG dimerization [67], whereas CDON and BOC can each directly bind to SHH.

\subsubsection{Non-canonical signaling pathway}

In addition to the classical typical HH-PTC-SMO pathway, there is increasing evidence that non-canonical signaling pathways for GLI activation also play significant roles. Non-canonical pathway refers to independent response of all cells and tissues to any factors in $\mathrm{HH}$ signaling pathway, and gets transcriptional changes mediated by the GLI family [14]. In some cancer type, canonical and non-canonical activation may co-exist [82].

The non-canonical pathway GLI-independent mechanisms can be identified of two types: Type I is about modulation of $\mathrm{Ca}^{2+}$ and actin cytoskeleton, which is downstream of SMO; while type II is signaling pathway that is independent on SMO [94].

There are kinds of non-canonical pathways that positively promote $\mathrm{HH}$ signal transduction, including RAS-RAF-MEK-ERK signaling pathway [92], PI3KAKT-mTOR signaling pathway [104], TGF $\beta$ signaling pathway [24]; and pathways that inhibit $\mathrm{HH}$ signaling such as MAPKKK-MEKK [4].

\section{$2 \mathrm{SHH}$ pathway functions in tissue development}

Previous study of experimental embryology shows that the organ development of embryo is mainly regulated by the so-called induced tissue interactions, which mostly occurs between epithelial tissues and mesenchymal tissues. SHH signaling pathway plays a crucial role in epithelial tissue development.

\subsection{Skin and its appendages}

\subsubsection{Epidermis}

In the vertebrate kingdom, epithelial appendages begin to form during embryogenesis, when progenitor cells within WNT signaling epithelium are lined up into morphologically similar substrates. After the formation of similar epidermal buds, the selection of appendages depends on the antagonism between bone morphogenetic proteins (BMPs) and SHH signals in different skin regions in the mesenchyme. When the $\mathrm{SHH}$ signal is active, it determines the formation of hair follicles (HFs). When SHH signal is weaker than BMP, it determines the formation of sweat glands [62]. SHH signals from epithelial mesenchyme affect the fate of skin appendages.

\subsubsection{Touch dome}

In the embryo, $\mathrm{SHH}$ signals from the epithelium also stimulate the formation of $\mathrm{Gli1}^{+}$cells and lead to an increase in Sox $9^{+}$cells, which develop into hair follicle stem cells (HFSCs) and hair follicle line cells. The researchers further confirm that Sox9-mediated fibroblast growth factor receptor2 (FGFR2) signals increase the production of Merkel cells (MCs), a tactile receptor, which is located in the touch dome (TD) [71]. The touch dome expresses keratin 17, and Merkel cells are located in it and adjacent to keratin 15 expressing keratinocytes.

When the placode begins to develop, SHH signals from the downstream of primary hair follicle development pathway Ectodysplasin A/Ectodysplasin A receptor (EDA/EDAR) affects the formation of TD MCs [143]. Other researchers have confirmed that loss of Polycomb Repressive Complex 2 (PRC2) in the epidermis results in the formation of ectopic Merkel cells. By upregulation of known PRC2 target genes, PRC2 deletion extends the range of differentiated epidermal cells to Merkel cells. Importantly, PRC2-mediated inhibition of the Merkel cell differentiation program requires the induction of $\mathrm{SHH}$ signals to form mature Merkel cells [80].

SHH signal of self-neurons also plays a crucial role in maintaining the development of touch dome. Skin denervation experiment suggests that the regeneration of touch dome stem cells needs a neural microenvironment. The removal of SHH from neurons or epidermal SMO indicates that $\mathrm{SHH}$ is a necessary niche factor for maintaining touch dome stem cells. Up-regulation of the $\mathrm{HH}$ signaling pathway results in tumor amplification of touch dome keratinocytes, but not neoplasia of Merkel cells. Neurogenic SHH is a key regulator of lineage-specific stem cells, maintaining the special sensory compartments of the epidermis. In conclusion, $\mathrm{SHH}$ is necessary for the development of touch dome. 


\subsubsection{Hair}

Hair follicle development can be divided into three stages: induction, organogenesis and cytodifferentiation [78]. HH signal transduction is crucial for both the transition from induction stage to organogenesis stage, and the downward growth of epithelial cells after induction stage. Mice lacking $\mathrm{SHH}$ produce hair placodes and dermal condensates, but the formation of hair follicles is blocked at the hairy bud stage $[19,109]$. At the beginning of the organogenesis stage in E15.5, PTC1, SMO, GLI1 and GLI2 can be detected in the dermal components of early hair follicles, indicating that $\mathrm{HH}$ signal also participate in regulation of dermal cells. SMO inhibition in hair cells mediated by RNAi results in the loss of the dermal papilla (DP) precursor and hair cell condensate, bringing out the result of cease growing during organogenesis, similar to similar to $\mathrm{SHH}^{-}$- skin. These results indicate that the dermal $\mathrm{SHH}$ signaling modulates specific DP signals to maintain DP maturity [140]. SHH signaling is not needed to start hair follicle development, but it is quite important to control hair follicle growth and morphogenesis.

In addition, the stem cells in the hair follicle bulge can regenerate hair follicles periodically, while the stem cell population maintaining the epidermis is unique. During telogen, GLI1 expression is limited to two different epidermal stem cell domains [16], $\mathrm{Gli}^{+} / \mathrm{Lgr}^{+}$stem cells in contact with hair germ and $\mathrm{Gli}^{+} / \mathrm{Sox} 9^{+}$stem cells in the upper fringe of the bulge $[6,135] . \mathrm{Gli}^{+} / \mathrm{Lgr}^{+}$stem cells are regulated by SHH signaling pathway in DP and differentiate into new hair follicle structures in the hair follicle growth cycle. The upper bulge that expresses GLI1 is induced by the release of SHH from nerve cells associated with bulge. Therefore, upper bulge cells may constitute a long-term stem cell bank, ready to contribute to the repair of the epidermis between follicles.

\subsubsection{Sebaceous gland}

The mature sebaceous glands (SGs) are the appendages of the total secretion of epidermal acini. As an important part of the pilosebaceous gland, SG is connected with the junction zone (JZ), which is located in the upper permanent part of HF. SG is the last lineage to develop at E16.5-E17.5 (bulbous peg stage) in the morphogenesis of $\mathrm{HF}$, which keeps a permanent relationship with the upper part of HF. HH signaling pathway is a typical signaling pathway involved in the proliferation of sebocytes. The expression of activated SMO in mouse epidermis leads to the formation of ectopic SGs. On the contrary, inhibition of HH signal by overexpression of dominant-negative GLI mutant can inhibit the differentiation of sebocytes [2]. The inhibition of $\mathrm{HH}$ pathway selectively inhibited the development of sebocytes, and the activation of $\mathrm{HH}$ pathway resulted in a significant increase in the size and number of sebaceous glands. In conclusion, $\mathrm{HH}$ pathway plays a key role in determining the fate of sebocytes and is a potential target for the treatment of skin disorders linked to abnormal sebaceous gland function.

\subsubsection{Mammary glands}

Mammary glands are highly specialized types of sweat glands [75]. There are three important stages of breast development: embryonic stage, pubertal stage and reproductive stage [138]. GLI3, a component of the $\mathrm{HH}$ signaling pathway, has recently been described to regulate the formation of bud [42]. After GLI3 is removed, GLI1 expression is inhibited in the mammary gland in the region of placode 3 , resulting in the loss or dislocation of bud-pairs 3 and 5. In E11 Gli3 xt/xt (extratoes mutant) mice, the absence of WNT signal reporter TOP-Gal in the central region of the mammary gland system suggests that the $\mathrm{HH}$ pathway inhibition mediated by GLI3 is necessary prior to early patterning events. Therefore, although $\mathrm{HH}$ pathway is active in epidermal appendages (such as HF), it is either inactive or inhibited during the development of mammary glands [86]. It is also interesting that the formation of $\mathrm{HF}$ is inhibited, which is conducive to the development of the mammary gland. Recently, it has been found in mice that the blocking of epithelial SHH signal leads to the transformation of some HFs into mammary-gland-like fate [34].

SHH plays an important role in breast cancer. Previous studies have shown that $\mathrm{SHH}$ is highly expressed in breast cancer, and the SHH-GLI feedback mechanism contributes to the occurrence and the development of breast cancer [118]. Increased GLI1 expression in breast cancer is associated with aggressive tumor behavior, resulting in higher tumor staging and lymph node status [116]. Compared with patients with low SHH expression level in tumor tissues, patients with high $\mathrm{SHH}$ expression level had significantly lower overall survival rate [74]. This conclusion is consistent with previous research by Li's team, that a significant correlation between high $\mathrm{HH} / \mathrm{SHH}$ expression and adverse prognostic factors exists [116].

\subsubsection{Tooth}

SHH plays a crucial role in many developmental pathways, including the tooth and nail. During early tooth development in mice, gene expressions including Ptc, Smo, Gli1, Gli2, and Gli3 are expressed in epithelium and mesenchyme, while SHH is only detected in epithelium, which suggests that $\mathrm{SHH}$ is involved in epithelial-stromal and epithelial signals in early tooth development [40]. Tissue reorganization studies have shown that in the early stages of tooth development, the expression of some molecules is indeed regulated by epithelial-mesenchymal interaction, especially in morphogenesis [120].

During tooth development, Shh expression has been shown to be localized in epithelial cells [53]. The expression of $S h h$ in the early stage of the epithelial thickening stage suggests that the signaling pathway may play a role in the formation of tooth germ and epithelial-mesenchymal interactions. The expression of Shh in enamel knot [125] 
is a signal center in the process of tooth development, which may participate in the formation of cusp by regulating the proliferation of tooth germ. The application of SHH protein in dental beads shows that the downstream gene of the pathway is activated in mesenchymal and the morphology of tooth bud is changed, indicating the role of $\mathrm{SHH}$ signal in the epithelial cell proliferation involved in the formation of tooth bud. The results further indicates that although SHH signaling pathway is necessary for the development of normal teeth, there is still functional redundancy between Gli genes. Only when Gli2 and Gli3 genes are absent can tooth development be mainly affected [40]. In addition to the GLI family, SUFU is also an important factor in regulating the development of mandibular [57].

\subsubsection{Nail}

Nail structure is consisted of the nail plate, keratin structure without living tissue and four different epithelial tissues: the nail bed, the nail plate, the nail matrix, four distinct epithelial tissues, a keratin structure with no living tissue, the hyponychium and perionychium [41]. The outer surface of each nail is convex, the inner surface is concave, and a part called root is implanted into the groove of the skin. the distal part is called the free edge, and the exposed part is called the body.

$\mathrm{SHH}$ plays a significant role in both the formation and development of nails. The appearance of nail from $\mathrm{SHH}^{-/-}$ hindlimb is slightly abnormal, which is flatter than the typical wild-type claw in perinatal period, and the middle part is limited. In addition to nails, paw pads also show different phenotypes in $\mathrm{SHH}^{-/-}$[54].

Since a nail normally forms in close proximity to the most distal phalange, the distalmost skeletal element in $\mathrm{SHH}^{-/-}$hind limbs may represent the distal phalanges due to their conical shape and rigid distal end [20].

\subsection{Other epithelial tissues}

\subsubsection{Gastric epithelium}

Several investigations have evidenced that $\mathrm{SHH}$ signaling pathway is also involved in the development of stomach. In Shh mutant mice, forestomach area, lined by squamous epithelium, is reduced; while the glandular epithelium of hind stomach is overgrowth [51]. These morphological changes are in accordance with Shh expression pattern, as in early stomach development from E11.5 to E15.5, Shh is highly expressed in the epithelium of forestomach but lower in the hindstomach [106]. Meanwhile, Pct1 expressed in mesenchyme show a similar expression pattern of Shh $[106,125]$. When Shh expression is disrupted resulting in high expression levels in both forestomach and hind stomach, the glandular epithelium is replaced by squamous epithelium and complex branched pits are replaced by simple unbranched pits [46]. These studies suggest that $\mathrm{SHH}$ signaling in stomach may inhibit the formation of glands. Intriguingly, the glandular stomach in Gli3 rather than
Gli2 knockout mice phenocopies that of Shh knockout mice [51], indicating that GLI3 plays a novel activation role in gastric development.

At E18.5 of the later development stage, Shh expression expands to the hind stomach, and $\mathrm{HH}$ signaling may no longer be exclusive to the mesenchyme, as both PTC1 and GLI1 can also be detected in the epithelial layer [89], which is similar to the adult stomach [9]. SHH derived from parietal cells could promote the mucous compartment expansion. It is worth noting that the postnatal development of stomachs cannot be deciphered for the early lethality of Shh knockout mice. The conditional inactivation of $\mathrm{HH}$ pathway components in the stomach is awaited to give more precise information [126].

It is now clear that the hedgehog signaling pathway plays a crucial role in gastric homeostasis. Abnormal activation of hedgehog signals is associated with a number of pathological consequences, such as nonatrophic gastritis (NAG) [90], chronic active gastritis (CAG) [72], intestinal metaplasia (IM) [110] and gastric cancer (GC) [1]. According to mortality data provided by the World Health Organization, Gastric Cancer is the fourth most common type of cancer and the second leading cause of cancer deaths worldwide, and is often diagnosed at an advanced stage [28]. SHH signaling pathway is of pivotal importance in cell proliferation, tumor growth and gastric cancer directly [3]. Two major molecules in the $\mathrm{HH}$ pathway, SHH and GLI, have been found in GC [139]. Besides, according to Samadani's research, SHH signaling may contribute to the survival of tumor cells, the exact role and mechanism are still unclear [99].

\subsubsection{Intestinal epithelium}

Early in the development of gut, Shh expressed in the endodermal epithelium induces its target gene $B m p 4$ expression in the splanchnic mesoderm, which negatively regulates differentiation of both intestinal smooth muscle and neuron formation [65,111]. Meanwhile, the formation of villi, one of the fundamental structures in the small intestinal mucosa, starts at E14.5 in mice when Shh expression is downregulated except for the duodenum [11]. In Shh mutant mice, villi in duodenum are overgrown and extensively branched, suggesting that $\mathrm{SHH}$ seems to restrict the growth of villi [65]. In contrast, IHH stimulates the villi formation as the hypoplastic and reduced number of villi are observed in Ihh mutants [89]. Consistent with that, when both $\mathrm{SHH}$ and IHH signaling pathways are blocked by Hhip overexpression, no villi will form, and the epithelium will remain pseudostratified and poorly differentiated with unfettered proliferation.

After birthing in rodents, crypts are given rise from the intervillous region, where $S h$ is mainly expressed after villi formation. The local diffusion of $\mathrm{SHH}$ and $\mathrm{IHH}$ within the crypt is thought to inhibit additional crypt formation, thereby guaranteeing orderly crypt spacing, and promoting normal villus development [91]. Moreover, both Shh 
and Ihh mutant mice exhibit malrotation of the gut [108], which is probably induced by disrupting the left-right axis formation [115].

SHH, PTC1, and SMO are detected in hyperplastic polyps, adenomas and adenocarcinomas of the colon of both human and mouse [128]. The growth of colon cancer cell lines in vitro could be inhibited by adding cyclopamine (inhibitors of SMO) [5]. Furthermore, abnormal HH pathway activity can indirectly promote colon cancer growth by activating the WNT pathway [129], which is detected active state in $90 \%$ of hereditary and sporadic colon cancers [65].

Mechanisms in tumors involves $\mathrm{HH}$ pathway can be described as 3 aspects [5]: (1) This pathway is activated by either functionally deficient mutations in inhibitory proteins (such as PTC1, SUFU) or functionally acquired mutations in positive regulators (such as SMO); (2) Overexpression of $\mathrm{HH}$ ligands acting in an autocrine/paracrine function to activate the $\mathrm{HH}$ pathway, and result in a feedback mitogen that induces tumor growth; (3) Overexpression of $\mathrm{HH}$ ligands leads to the regeneration of tumor stem cells.

\section{Perspective}

$\mathrm{HH}$ signal is a kind of evolutionarily conserved signaling pathway, which is crucial to cell fate and selfrenewal. It has been reported that abnormal HH signal is related to various cancers and other diseases [55], for which scientists have put lots of efforts into studying its function.

In adults, abnormal activation of $\mathrm{HH}$ signal is related to congenital disabilities and multiple solid cancers in gastric cancer cell lines, Shh is highly expressed, and promotes the transformation of tumor [1]. It is also reported that $S h h$ and Gli are overexpressed in pancreatic cancer, which suggested that SHH and GLI can be used as prognostic indicators [66]. In addition, the abnormal expression of $S h h$ is related to the low survival rate in nonsmall cell lung cancer (NSCLC). The inhibition of SHH has a significant effect on the invasion and migration of lung cancer cells [48]. Recent clinical results show that inhibiting this pathway has therapeutic benefits. For example, SMO has critical roles in the $\mathrm{HH}$ and is a drug target in the treatment of various cancers [102]. Therefore, the basic knowledge of F-GPCRs activation is of great significance not only to reveal the signal transduction mechanism of $\mathrm{HH}$ and WNT, but also to develop the therapeutic approaches for clinical application [121,122]. Thus, it is crucial to explore how HH signaling pathway functions in different tissues in order to give insight into the mechanism of HH-related diseases.

Other signal pathways or factors act synergistic roles in HH signaling. It has been reported that GLI could be activated by RAS/AKT, Peptidase Inhibitor 3 (PI3)Kinase/AKT, rather than $\mathrm{HH}[93,107]$. Although the role of these regulations in development has not been completely unmasked, the interaction and relationship between them remain to be further explored. Biological effects of $\mathrm{HH}$ signal may depend on tissue-specific factors and other spatiotemporal regulatory signals, such as epigentic regulation which are unclear. To get new insight into how $\mathrm{HH}$ signaling pathway functions in cell fate and stem cell self-renewal, as well as in disease, the mechanism of synergetic regulation of canonical and noncanonical $\mathrm{HH}$ signaling pathway, especially what's the molecular switch and how they function, needs to be further investigated.

\section{Funding}

This project is supported by the scientific research start-up funds for specially engaged employees of Sir Run Run Shaw Hospital (Ytp1902), the National Nature Science Foundation of China (31900620), and Open fund for scientific research of Zhe Jiang Chinese Medical University (ZYXZD2019003).

Acknowledgments. Thank Dr. Sadaruddin Chachar for manuscript reviewing.

\section{Conflict of interest}

The authors declare that there is no financial or other relationship that might lead to a conflict of the present article. All authors have reviewed the final version of the manuscript and approved it for publication.

\section{References}

1. Akyala AI, Peppelenbosch MP (2018), Gastric cancer and Hedgehog signaling pathway: emerging new paradigms. Genes Cancer 9, 1-10.

2. Allen M, Grachtchouk M, Sheng H, Grachtchouk V, Wang A, Wei L, Liu J, Ramirez A, Metzger D, Chambon P, Jorcano J, Dlugosz AA (2003), Hedgehog signaling regulates sebaceous gland development. Am J Pathol 163, $2173-2178$.

3. Almeida R, Almeida J, Shoshkes M, Mendes N, Mesquita P, Silva E, Van Seuningen I, Reis CA, Santos-Silva F, David L (2005), OCT-1 is over-expressed in intestinal metaplasia and intestinal gastric carcinomas and binds to, but does not transactivate, CDX2 in gastric cells. J Pathol 207, 396-401.

4. Antonucci L, Di Magno L, D'Amico D, Manni S, Serrao SM, Di Pastena F, Bordone R, Yurtsever ZN, Caimano M, Petroni M, Giorgi A, Schinina ME, Yates IJ, Di Marcotullio L, De Smaele E, Checquolo S, Capalbo C, Agostinelli E, Maroder M, Coni S, Canettieri G (2019), Mitogen-activated kinase kinase kinase 1 inhibits hedgehog signaling and medulloblastoma growth through GLI1 phosphorylation. Int J Oncol 54, 505-514.

5. Barakat MT, Humke EW, Scott MP (2010), Learning from Jekyll to control Hyde: Hedgehog signaling in development and cancer. Trends Mol Med 16, 337-348.

6. Barker N, van Es JH, Jaks V, Kasper M, Snippert H, Toftgard R, Clevers H (2008), Very long-term self-renewal of small intestine, colon, and hair follicles from cycling Lgr $5+$ ve stem cells. Cold Spring Harb Symp Quant Biol 73, 351-356.

7. Beauchamp EM, Ringer L, Bulut G, Sajwan KP, Hall MD, Lee YC, Peaceman D, Ozdemirli M, Rodriguez O, Macdonald TJ, Albanese C, Toretsky JA, Uren A 
(2011), Arsenic trioxide inhibits human cancer cell growth and tumor development in mice by blocking Hedgehog/ GLI pathway. J Clin Invest 121, 148-160.

8. Berbari NF, O'Connor AK, Haycraft CJ, Yoder BK (2009), The primary cilium as a complex signaling center. Curr Biol 19, R526-R535.

9. Berman DM, Karhadkar SS, Maitra A, Montes DOR, Gerstenblith MR, Briggs K, Parker AR, Shimada Y, Eshleman JR, Watkins DN, Beachy PA (2003), Widespread requirement for Hedgehog ligand stimulation in growth of digestive tract tumours. Nature 425 , 846-851.

10. Bijlsma MF, Spek CA, Zivkovic D, van de Water S, Rezaee F, Peppelenbosch MP (2006), Repression of smoothened by patched-dependent (pro-)vitamin D3 secretion. Plos Biol 4, e232.

11. Bitgood MJ, McMahon AP (1995), Hedgehog and Bmp genes are coexpressed at many diverse sites of cellcell interaction in the mouse embryo. Dev Biol 172, 126-138.

12. Borzillo GV, Lippa B (2005), The Hedgehog signaling pathway as a target for anticancer drug discovery. Curr Top Med Chem 5, 147-157.

13. Bosanac I, Maun HR, Scales SJ, Wen X, Lingel A, Bazan JF, de Sauvage FJ, Hymowitz SG, Lazarus RA (2009), The structure of SHH in complex with HHIP reveals a recognition role for the Shh pseudo active site in signaling. Nat Struct Mol Biol 16, 691-697.

14. Brennan D, Chen X, Cheng L, Mahoney M, Riobo NA (2012), Noncanonical Hedgehog signaling. Vitam Horm $88,55-72$.

15. Briscoe J, Therond PP (2013), The mechanisms of Hedgehog signalling and its roles in development and disease. Nat Rev Mol Cell Biol 14, 416-429.

16. Brownell I, Guevara E, Bai CB, Loomis CA, Joyner AL (2011), Nerve-derived sonic hedgehog defines a niche for hair follicle stem cells capable of becoming epidermal stem cells. Cell stem cell 8, 552-565.

17. Chavez M, Ena S, Van Sande J, de Kerchove DA, Schurmans S, Schiffmann SN (2015), Modulation of Ciliary Phosphoinositide Content Regulates Trafficking and Sonic Hedgehog Signaling Output. Dev Cell 34, 338-350.

18. Chen Y, Struhl G (1998), In vivo evidence that Patched and Smoothened constitute distinct binding and transducing components of a Hedgehog receptor complex. Development. 125, 4943-4948.

19. Chiang C, Swan RZ, Grachtchouk M, Bolinger M, Litingtung Y, Robertson EK, Cooper MK, Gaffield W, Westphal H, Beachy PA, Dlugosz AA (1999), Essential role for Sonic hedgehog during hair follicle morphogenesis. Dev Biol 205, 1-9.

20. Chiang C, Litingtung Y, Lee E, Young KE, Corden JL, Westphal H, Beachy PA (1996), Cyclopia and defective axial patterning in mice lacking Sonic hedgehog gene function. Nature 383, 407-413.

21. Chuang PT, McMahon AP (1999), Vertebrate Hedgehog signalling modulated by induction of a Hedgehog-binding protein. Nature 397, 617-621.

22. Corbit KC, Aanstad P, Singla V, Norman AR, Stainier DY, Reiter JF (2005), Vertebrate Smoothened functions at the primary cilium. Nature 437, 1018-1021.

23. Davenport JR, Yoder BK (2005), An incredible decade for the primary cilium: a look at a once-forgotten organelle. Am J Physiol Renal Physiol 289, F1159- F1169.
24. Dennler S, Andre J, Verrecchia F, Mauviel A (2009), Cloning of the human GLI2 Promoter: transcriptional activation by transforming growth factor-beta via SMAD3/beta-catenin cooperation. J Biol Chem 284, 31523-31531.

25. Endoh-Yamagami S, Evangelista M, Wilson D, Wen X, Theunissen JW, Phamluong K, Davis M, Scales SJ, Solloway MJ, de Sauvage FJ, Peterson AS (2009), The mammalian Cos2 homolog Kif7 plays an essential role in modulating Hh signal transduction during development. Curr Biol 19, 1320-1326.

26. Ericson J, Morton S, Kawakami A, Roelink H, Jessell TM (1996), Two critical periods of Sonic Hedgehog signaling required for the specification of motor neuron identity. Cell 87, 661-673.

27. Fan J, Zhang X, Wang S, Chen W, Li Y, Zeng X, Wang Y, Luan J, Li L, Wang Z, Sun X, Shen B, Ju D (2019), Regulating autophagy facilitated therapeutic efficacy of the sonic Hedgehog pathway inhibition on lung adenocarcinoma through GLI2 suppression and ROS production. Cell Death Dis 10, 626.

28. Ferro A, Peleteiro B, Malvezzi M, Bosetti C, Bertuccio P, Levi F, Negri E, La Vecchia C, Lunet N (2014), Worldwide trends in gastric cancer mortality (1980-2011), with predictions to 2015 , and incidence by subtype. Eur J Cancer 50, 1330-1344.

29. Ferruzzi P, Mennillo F, De Rosa A, Giordano C, Rossi M, Benedetti G, Magrini R, Pericot MG, Miragliotta V, Magnoni L, Mori E, Thomas R, Tunici P, Bakker A (2012), In vitro and in vivo characterization of a novel Hedgehog signaling antagonist in human glioblastoma cell lines. Int J Cancer 131, E33-E44.

30. Frank-Kamenetsky M, Zhang XM, Bottega S, Guicherit O, Wichterle H, Dudek H, Bumcrot D, Wang FY, Jones S, Shulok J, Rubin LL, Porter JA (2002), Small-molecule modulators of Hedgehog signaling: identification and characterization of Smoothened agonists and antagonists. J Biol 1, 10

31. Fuse N, Maiti T, Wang B, Porter JA, Hall TM, Leahy DJ, Beachy PA (1999), Sonic hedgehog protein signals not as a hydrolytic enzyme but as an apparent ligand for patched. Proc Natl Acad Sci U S A 96, 10992-10999.

32. Goldstein JL, DeBose-Boyd RA, Brown MS (2006), Protein sensors for membrane sterols. Cell 124, $35-46$

33. Gorojankina T, Hoch L, Faure H, Roudaut H, Traiffort E Schoenfelder A, Girard N, Mann A, Manetti F, Solinas A, Petricci E, Taddei M, Ruat M (2013), Discovery, molecular and pharmacological characterization of GSA-10, a novel small-molecule positive modulator of Smoothened. Mol Pharmacol 83, 1020-1029.

34. Gritli-Linde A, Hallberg K, Harfe BD, Reyahi A, Kannius M, Nilsson-Janson J, Cobourne MT, Sharpe PT, McMahon AP, Linde A (2007), Abnormal hair development and apparent follicular transformation to mammary gland in the absence of hedgehog signaling. Dev Cell 12, 99-112.

35. Hall TM, Porter JA, Young KE, Koonin EV, Beachy PA, Leahy DJ (1997), Crystal structure of a Hedgehog autoprocessing domain: homology between Hedgehog and self-splicing proteins. Cell 91, 85-97.

36. Hall TM, Porter JA, Beachy PA, Leahy DJ (1995), A potential catalytic site revealed by the 1.7-A crystal structure of the amino-terminal signalling domain of Sonic hedgehog. Nature 378, 212-216. 
37. Hammerschmidt M, Brook A, McMahon AP (1997), The world according to hedgehog. Trends Genet 13, $14-21$

38. Han Y, Shi Q, Jiang J (2015), Multisite interaction with Sufu regulates $\mathrm{Ci} /$ Gli activity through distinct mechanisms in Hh signal transduction. Proc Natl Acad Sci U S A $112,6383-6388$.

39. Haraguchi R, Motoyama J, Sasaki H, Satoh Y, Miyagawa S, Nakagata N, Moon A, Yamada G (2007), Molecular analysis of coordinated bladder and urogenital organ formation by Hedgehog signaling. Development 134, $525-533$.

40. Hardcastle Z, Mo R, Hui CC, Sharpe PT (1998), The Shh signalling pathway in tooth development: defects in Gli2 and Gli3 mutants. Development 125, 2803-2811.

41. Hasegawa K, Pereira BP, Pho RW (2001), The microvasculature of the nail bed, nail matrix, and nail fold of a normal human fingertip. J Hand Surg Am 26, 283-290.

42. Hatsell SJ, Cowin P (2006), Gli3-mediated repression of Hedgehog targets is required for normal mammary development. Development. 133, 3661-3670.

43. Huang P, Nedelcu D, Watanabe M, Jao C, Kim Y, Liu J, Salic A (2016), Cellular Cholesterol Directly Activates Smoothened in Hedgehog Signaling. Cell 166, 1176-1187.

44. Ingham PW, McMahon AP (2001), Hedgehog signaling in animal development: paradigms and principles. Genes Dev 15, 3059-3087.

45. Ingham PW, Nakano Y, Seger C (2011), Mechanisms and functions of Hedgehog signalling across the metazoa. Nat Rev Genet 12, 393-406.

46. Jacobsen CM, Narita N, Bielinska M, Syder AJ, Gordon JI, Wilson DB (2002), Genetic mosaic analysis reveals that GATA-4 is required for proper differentiation of mouse gastric epithelium. Dev Biol 241, 34-46.

47. Jiang K, Liu Y, Fan J, Zhang J, Li XA, Evers BM, Zhu H, Jia J (2016), PI(4)P Promotes Phosphorylation and Conformational Change of Smoothened through Interaction with Its C-terminal Tail. Plos Biol 14, e1002375.

48. Jiang WG, Ye L, Ruge F, Sun PH, Sanders AJ, Ji K, Lane J, Zhang L, Satherley L, Weeks HP, Zhi X, Gao Y, Wei C, Wu Y, Mason MD (2015), Expression of Sonic Hedgehog (SHH) in human lung cancer and the impact of YangZheng XiaoJi on SHH-mediated biological function of lung cancer cells and tumor growth. Anticancer Res 35, 1321-1331.

49. Karp SJ, Schipani E, St-Jacques B, Hunzelman J, Kronenberg H, McMahon AP (2000), Indian hedgehog coordinates endochondral bone growth and morphogenesis via parathyroid hormone related-protein-dependent and -independent pathways. Development 127, 543-548.

50. Kim J, Hsia EY, Brigui A, Plessis A, Beachy PA, Zheng X (2015), The role of ciliary trafficking in Hedgehog receptor signaling. Sci Signal 8, a55.

51. Kim JH, Huang Z, Mo R (2005), Gli3 null mice display glandular overgrowth of the developing stomach. Dev Dyn 234, 984-991.

52. Klejnot M, Kozielski F (2012), Structural insights into human Kif7, a kinesin involved in Hedgehog signalling. Acta Crystallogr D Biol Crystallogr 68, 154-159

53. Koyama E, Yamaai T, Iseki S, Ohuchi H, Nohno T, Yoshioka H, Hayashi Y, Leatherman JL, Golden EB, Noji S, Pacifici M (1996), Polarizing activity, Sonic hedgehog, and tooth development in embryonic and postnatal mouse. Dev Dyn 206, 59-72.

54. Kraus P, Fraidenraich D, Loomis CA (2001), Some distal limb structures develop in mice lacking Sonic hedgehog signaling. Mech Dev 100, 45-58.
55. Lawrie CH (2014) MicroRNAs in medicine p. 702

56. Lewis MT, Veltmaat JM (2004), Next stop, the twilight zone: hedgehog network regulation of mammary gland development. J Mammary Gland Biol Neoplasia 9, $165-181$.

57. Li J, Xu J, Cui Y, Wang L, Wang B, Wang Q, Zhang X, Qiu M, Zhang Z (2019), Mesenchymal Sufu Regulates Development of Mandibular Molars via Shh Signaling. J Dent Res 98, 1348-1356.

58. Liem KJ, He M, Ocbina PJ, Anderson KV (2009), Mouse Kif7/Costal2 is a cilia-associated protein that regulates Sonic hedgehog signaling. Proc Natl Acad Sci U S A 106, 13377-13382.

59. Lim A, Shin K, Zhao C, Kawano S, Beachy PA (2014), Spatially restricted Hedgehog signalling regulates HGFinduced branching of the adult prostate. Nat Cell Biol 16 , $1135-1145$.

60. Litingtung Y, Dahn RD, Li Y, Fallon JF, Chiang C (2002), Shh and Gli3 are dispensable for limb skeleton formation but regulate digit number and identity. Nature 418, 979-983.

61. Liu C, Peng J, Matzuk MM, Yao HH (2015), Lineage specification of ovarian theca cells requires multicellular interactions via oocyte and granulosa cells. Nat Commun 6, 6934 .

62. Lu, CP, Polak L, Keyes BE, Fuchs E (2016), Spatiotemporal antagonism in mesenchymal-epithelial signaling in sweat versus hair fate decision. Science 354 .

63. Luchetti G, Sircar R, Kong JH, Nachtergaele S, Sagner A, Byrne EF, Covey DF, Siebold C, Rohatgi R (2016), Cholesterol activates the G-protein coupled receptor Smoothened to promote Hedgehog signaling. Elife 5.

64. Lum L, Yao S, Mozer B, Rovescalli A, Von Kessler D, Nirenberg M, Beachy PA (2003), Identification of Hedgehog pathway components by RNAi in Drosophila cultured cells. Science 299, 2039-2045.

65. Madison BB, Braunstein K, Kuizon E, Portman K, Qiao XT, Gumucio DL (2005), Epithelial hedgehog signals pattern the intestinal crypt-villus axis. Development 132, 279-289.

66. Marechal R, Bachet JB, Calomme A, Demetter P, Delpero JR, Svrcek M, Cros J, Bardier-Dupas A, Puleo F, Monges G, Hammel P, Louvet C, Paye F, Bachelier P, Le Treut YP, Vaillant JC, Sauvanet A, Andre T, Salmon I, Deviere J, Emile JF, Van Laethem JL (2015), Sonic hedgehog and Gli1 expression predict outcome in resected pancreatic adenocarcinoma. Clin Cancer Res $21,1215-1224$

67. McLellan JS, Yao S, Zheng X, Geisbrecht BV, Ghirlando R, Beachy PA, Leahy DJ (2006), Structure of a heparindependent complex of Hedgehog and Ihog. Proc Natl Acad Sci U S A 103, 17208-17213.

68. Mukhopadhyay S, Wen X, Ratti N, Loktev A, Rangell L, Scales SJ, Jackson PK (2013), The ciliary G-proteincoupled receptor Gpr161 negatively regulates the Sonic hedgehog pathway via cAMP signaling. Cell 152, 210-223.

69. Myers BR, Sever N, Chong YC, Kim J, Belani JD, Rychnovsky S, Bazan JF, Beachy PA (2013), Hedgehog pathway modulation by multiple lipid binding sites on the smoothened effector of signal response. Dev Cell 26, 346-357.

70. Nachtergaele S, Whalen DM, Mydock LK, Zhao Z, Malinauskas T, Krishnan K, Ingham PW, Covey DF, Siebold C, Rohatgi R (2013), Structure and function of the Smoothened extracellular domain in vertebrate Hedgehog signaling. Elife 2, e1340. 
71. Nguyen MB, Cohen I, Kumar V, Xu Z, Bar C, DauberDecker KL, Tsai PC, Marangoni P, Klein OD, Hsu YC, Chen T, Mikkola ML, Ezhkova E (2018), Publisher Correction: FGF signalling controls the specification of hair placode-derived SOX9 positive progenitors to Merkel cells. Nat Commun 9, 2854.

72. Nishizawa T, Suzuki H, Nakagawa I, Minegishi Y, Masaoka T, Iwasaki E, Hibi T (2009), Rebamipidepromoted restoration of gastric mucosal sonic hedgehog expression after early Helicobacter pylori eradication. Digestion 79, 259-262.

73. Niyaz M, Khan MS, Mudassar S (2019), Hedgehog Signaling: An Achilles' Heel in Cancer. Transl Oncol 12, 1334-1344.

74. Noman AS, Uddin M, Rahman MZ, Nayeem MJ, Alam SS, Khatun Z, Wahiduzzaman M, Sultana A, Rahman ML, Ali MY, Barua D, Ahmed I, Islam MS, Aboussekhra A, Yeger H, Farhat WA, Islam SS (2016), Overexpression of sonic hedgehog in the triple negative breast cancer: clinicopathological characteristics of high burden breast cancer patients from Bangladesh. Sci Rep 6, 18830.

75. Oftedal OT (2002), The mammary gland and its origin during synapsid evolution. J Mammary Gland Biol Neoplasia 7, 225-252.

76. Pal K, Hwang SH, Somatilaka B, Badgandi H, Jackson PK, DeFea K, Mukhopadhyay S (2016), Smoothened determines beta-arrestin-mediated removal of the $G$ protein-coupled receptor Gpr161 from the primary cilium. J Cell Biol 212, 861-875.

77. Pan YB, Gong Y, Ruan HF, Pan LY, Wu XK, Tang C, Wang CJ, Zhu HB, Zhang ZM, Tang LF, Zou CC, Wang HB, Wu XM (2015), Sonic hedgehog through Gli2 and Gli3 is required for the proper development of placental labyrinth. Cell Death Dis 6, e1653.

78. Paus R, Muller-Rover S, Van Der Veen C, Maurer M, Eichmuller S, Ling G, Hofmann U, Foitzik K, Mecklenburg L, Handjiski B (1999), A comprehensive guide for the recognition and classification of distinct stages of hair follicle morphogenesis. J Invest Dermatol $113,523-532$

79. Pepinsky RB, Rayhorn P, Day ES, Dergay A, Williams KP, Galdes A, Taylor FR, Boriack-Sjodin PA, Garber EA (2000), Mapping sonic hedgehog-receptor interactions by steric interference. J Biol Chem 275, 10995-11001.

80. Perdigoto CN, Dauber KL, Bar C, Tsai PC, Valdes VJ, Cohen I, Santoriello FJ, Zhao D, Zheng D, Hsu YC, Ezhkova E (2016), Polycomb-Mediated Repression and Sonic Hedgehog Signaling Interact to Regulate Merkel Cell Specification during Skin Development. Plos Genet 12, e1006151.

81. Petrova E, Rios-Esteves J, Ouerfelli O, Glickman JF, Resh MD (2013), Inhibitors of Hedgehog acyltransferase block Sonic Hedgehog signaling. Nat Chem Biol 9, 247-249.

82. Pietrobono S, Gagliardi S, Stecca B (2019), Non-canonical Hedgehog Signaling Pathway in Cancer: Activation of GLI Transcription Factors Beyond Smoothened. Front Genet 10, 556.

83. Porter JA, Young KE, Beachy PA (1996), Cholesterol modification of hedgehog signaling proteins in animal development. Science 274, 255-259.

84. Porter JA, Ekker SC, Park WJ, von DP, Kessler, Young KE, Chen CH, Ma Y, Woods AS, Cotter RJ, Koonin EV, Beachy PA (1996), Hedgehog patterning activity: role of a lipophilic modification mediated by the carboxy-terminal autoprocessing domain. Cell 86, 21-34.
85. Praetorius HA, Spring KR (2005), A physiological view of the primary cilium. Annu Rev Physiol. 67, $515-529$.

86. Qi X, Schmiege P, Coutavas E, Wang J, Li X (2018), Structures of human Patched and its complex with native palmitoylated sonic hedgehog. Nature 560, $128-132$.

87. Qi X, Schmiege P, Coutavas E, Li X (2018), Two Patched molecules engage distinct sites on Hedgehog yielding a signaling-competent complex. Science 362 .

88. Qi X, Liu H, Thompson B, McDonald J, Zhang C, Li X (2019), Cryo-EM structure of oxysterol-bound human Smoothened coupled to a heterotrimeric Gi. Nature 571, 279-283.

89. Ramalho-Santos M, Melton DA, McMahon AP (2000), Hedgehog signals regulate multiple aspects of gastrointestinal development. Development 127, 2763-2772.

90. Rau T, Dimmler A, Hafner M, Brabletz T, Kirchner T, Faller G (2005), Aberrant expression of TTF-1 and forkhead factor HFH-4 in atrophic gastritis and ciliated metaplasia suggests gastric broncho-pulmonary transdetermination. J Pathol. 206, 383-387.

91. Richmond CA, Breault DT (2010), Regulation of gene expression in the intestinal epithelium. Prog Mol Biol Transl Sci 96, 207-229.

92. Riobo NA, Haines GM, Emerson CJ (2006), Protein kinase C-delta and mitogen-activated protein/extracellular signal-regulated kinase-1 control GLI activation in hedgehog signaling. Cancer Res 66, 839-845.

93. Riobo NA, Lu K, Ai X, Haines GM, Emerson CJ (2006), Phosphoinositide 3-kinase and Akt are essential for Sonic Hedgehog signaling. Proc Natl Acad Sci U S A 103, 4505-4510.

94. Robbins DJ, Fei DL, Riobo NA (2012), The Hedgehog signal transduction network. Sci Signal 5, e6.

95. Roessler E, Muenke M (1998), Holoprosencephaly: a paradigm for the complex genetics of brain development. J inherit metab dis $21,481-497$.

96. Rohatgi R, Scott MP (2007), Patching the gaps in Hedgehog signalling. Nat Cell Biol 9, 1005-1009.

97. Rosenblum JS, Blobel G (1999), Autoproteolysis in nucleoporin biogenesis. Proc Natl Acad Sci U S A 96, 11370-11375

98. Ruiz IAA, Sanchez P, Dahmane N (2002), Gli and hedgehog in cancer: tumours, embryos and stem cells. Nat Rev Cancer 2, 361-372.

99. Samadani AA, Akhavan-Niaki H (2015), Interaction of sonic hedgehog (SHH) pathway with cancer stem cell genes in gastric cancer. Med Oncol 32, 48.

100. Scales SJ, de Sauvage FJ (2009), Mechanisms of Hedgehog pathway activation in cancer and implications for therapy. Trends Pharmacol Sci 30, 303-312.

101. Sever N, Mann RK, Xu L, Snell WJ, Hernandez-Lara CI, Porter NA, Beachy PA (2016), Endogenous B-ring oxysterols inhibit the Hedgehog component Smoothened in a manner distinct from cyclopamine or side-chain oxysterols. Proc Natl Acad Sci U S A 113.

102. Sharpe HJ, Wang W, Hannoush RN, de Sauvage FJ (2015), Regulation of the oncoprotein Smoothened by small molecules. Nat Chem Biol 11, 246-255.

103. Shimada IS, Hwang SH, Somatilaka BN, Wang X, Skowron P, Kim J, Kim M, Shelton JM, Rajaram V, Xuan Z, Taylor MD, Mukhopadhyay S (2018), Basal Suppression of the Sonic Hedgehog Pathway by the G-Protein-Coupled Receptor Gpr161 Restricts Medulloblastoma Pathogenesis. Cell Rep 22, 1169-1184. 
104. Singh R, Dhanyamraju PK, Lauth M (2017), DYRK1B blocks canonical and promotes non-canonical Hedgehog signaling through activation of the mTOR/AKT pathway. Oncotarget 8, 833-845.

105. Sinha S, Chen JK (2006), Purmorphamine activates the Hedgehog pathway by targeting Smoothened. Nat Chem Biol 2, 29-30

106. Spencer-Dene B, Sala FG, Bellusci S, Gschmeissner S, Stamp G, Dickson C (2006), Stomach development is dependent on fibroblast growth factor 10/fibroblast growth factor receptor 2b-mediated signaling. Gastroenterology 130, 1233-1244.

107. Stecca B, Mas C, Clement V, Zbinden M, Correa R, Piguet V, Beermann F, Ruiz IAA (2007), Melanomas require HEDGEHOG-GLI signaling regulated by interactions between GLI1 and the RAS-MEK/AKT pathways. Proc Natl Acad Sci U S A 104, 5895-5900.

108. Stepan V, Ramamoorthy S, Nitsche H, Zavros Y, Merchant JL, Todisco A (2005), Regulation and function of the sonic hedgehog signal transduction pathway in isolated gastric parietal cells. J Biol Chem 280, 15700-15708.

109. St-Jacques B, Dassule HR, Karavanova I, Botchkarev VA, Li J, Danielian PS, McMahon JA, Lewis PM, Paus R, McMahon AP (1998), Sonic hedgehog signaling is essential for hair development. Curr Biol 8, 1058-1068.

110. Strobel O, Rosow DE, Rakhlin EY, Lauwers GY, Trainor AG, Alsina J, Fernandez-Del CC, Warshaw AL, Thayer SP (2010), Pancreatic duct glands are distinct ductal compartments that react to chronic injury and mediate Shhinduced metaplasia. Gastroenterology 138, 1166-1177.

111. Sukegawa A, Narita T, Kameda T, Saitoh K, Nohno T, Iba H, Yasugi S, Fukuda K (2000), The concentric structure of the developing gut is regulated by Sonic hedgehog derived from endodermal epithelium. Development 127, $1971-1980$

112. Taipale J, Cooper MK, Maiti T, Beachy PA (2002), Patched acts catalytically to suppress the activity of Smoothened. Nature 418, 892-897.

113. Taipale J, Chen JK, Cooper MK, Wang B, Mann RK, Milenkovic L, Scott MP. Beachy PA (2000), Effects of oncogenic mutations in Smoothened and Patched can be reversed by cyclopamine. Nature 406, 1005-1009.

114. Takizawa N, Tanaka S, Oe S, Koike T, Yoshida T, Hirahara Y, Matsuda T, Yamada H (2018), Involvement of DHH and GLI1 in adrenocortical autograft regeneration in rats. Sci Rep 8, 14542.

115. Tanaka Y, Okada Y, Hirokawa N (2005), FGF-induced vesicular release of Sonic hedgehog and retinoic acid in leftward nodal flow is critical for left-right determination. Nature 435, 172-177.

116. Tao Y, Mao J, Zhang Q, Li L (2011), Overexpression of Hedgehog signaling molecules and its involvement in triple-negative breast cancer. Oncol Lett 2, 995-1001.

117. Te WP, Zuniga A, Kuijper S, Drenth T, Goedemans HJ, Meijlink F, Zeller R (2002), Progression of vertebrate limb development through SHH-mediated counteraction of GLI3. Science 298, 827-830.

118. Ten HA, Bektas N, von Serenyi S, Losen I, Arweiler EC, Hartmann A, Knuchel R, Dahl E (2009), Expression of the glioma-associated oncogene homolog (GLI) 1 in human breast cancer is associated with unfavourable overall survival. BMC Cancer 9, 298.

119. Tenzen T, Allen BL, Cole F, Kang JS, Krauss RS, McMahon AP (2006), The cell surface membrane proteins Cdo and Boc are components and targets of the Hedgehog signaling pathway and feedback network in mice. Dev Cell $10,647-656$.
120. Thesleff I, Vaahtokari A, Kettunen P, Aberg T (1995), Epithelial-mesenchymal signaling during tooth development. Connect Tissue Res 32, 9-15.

121. Traiffort E, Charytoniuk DA, Faure H, Ruat M (1998), Regional distribution of Sonic Hedgehog, patched, and smoothened mRNA in the adult rat brain. J Neurochem 70, 1327-1330.

122. Traiffort E, Charytoniuk D, Watroba L, Faure H, Sales N, Ruat M (1999), Discrete localizations of hedgehog signalling components in the developing and adult rat nervous system. Eur J Neurosci 11, 3199-3214.

123. Tremblay MR, Lescarbeau A, Grogan MJ, Tan E, Lin G, Austad BC, Yu LC, Behnke ML, Nair SJ, Hagel M, White K, Conley J, Manna JD, Alvarez-Diez TM, Hoyt J, Woodward CN, Sydor JR, Pink M, MacDougall J, Campbell MJ, Cushing J, Ferguson J, Curtis MS, McGovern K, Read MA, Palombella VJ, Adams J, Castro AC (2009), Discovery of a potent and orally active hedgehog pathway antagonist (IPI-926). J Med Chem 52, 4400-4418.

124. Tukachinsky H, Petrov K, Watanabe M, Salic A (2016), Mechanism of inhibition of the tumor suppressor Patched by Sonic Hedgehog. Proc Natl Acad Sci U S A 113, E5866E5875.

125. Vaahtokari A, Aberg T, Jernvall J, Keranen S, Thesleff I (1996), The enamel knot as a signaling center in the developing mouse tooth. Mech Dev 54, 39-43.

126. van den Brink GR (2007), Hedgehog signaling in development and homeostasis of the gastrointestinal tract. Physiol Rev 87, 1343-1375.

127. van den Brink GR, Bleuming SA, Hardwick JC, Schepman BL, Offerhaus GJ, Keller JJ, Nielsen C, Gaffield W, van Deventer SJ, Roberts DJ, Peppelenbosch MP (2004), Indian Hedgehog is an antagonist of Wnt signaling in colonic epithelial cell differentiation. Nat Genet 36, 277-282.

128. Van Den Brink GR, Peppelenbosch MP (2006), Expression of hedgehog pathway components in the adult colon. Gastroenterology 130, 619.

129. Varnat F, Duquet A, Malerba M, Zbinden M, Mas C, Gervaz P, Ruiz IAA (2009), Human colon cancer epithelial cells harbour active HEDGEHOG-GLI signalling that is essential for tumour growth, recurrence, metastasis and stem cell survival and expansion. Embo Mol Med 1, 338-351.

130. Villavicencio EH, Walterhouse DO, Iannaccone PM (2000), The sonic hedgehog-patched-gli pathway in human development and disease. Am J Hum Genet 67, 1047-1054.

131. Vortkamp A, Lee K, Lanske B, Segre GV, Kronenberg HM, Tabin CJ (1996), Regulation of rate of cartilage differentiation by Indian hedgehog and PTH-related protein. Science 273, 613-622.

132. Wang B, Fallon JF, Beachy PA (2000), Hedgehogregulated processing of Gli3 produces an anterior/ posterior repressor gradient in the developing vertebrate limb. Cel 100, 423-434.

133. Wang C, Wu H, Katritch V, Han GW, Huang XP, Liu W, Siu FY, Roth BL, Cherezov V, Stevens RC (2013), Structure of the human smoothened receptor bound to an antitumour agent. Nature 497, 338-343.

134. Wang C, Wu H, Evron T, Vardy E, Han GW, Huang XP, Hufeisen SJ, Mangano TJ, Urban DJ, Katritch V, Cherezov V, Caron MG, Roth BL, Stevens RC (2014), Structural basis for Smoothened receptor modulation and chemoresistance to anticancer drugs. Nat Commun 5 , 4355 . 
135. Wang LC, Liu ZY, Gambardella L, Delacour A, Shapiro R, Yang J, Sizing I, Rayhorn P, Garber EA, Benjamin CD, Williams KP, Taylor FR, Barrandon Y, Ling L, Burkly LC (2000), Regular articles: conditional disruption of hedgehog signaling pathway defines its critical role in hair development and regeneration. J Invest Dermatol 114, 901-908.

136. Wang Y, Zeng H, Liu A (2019), Distinct Activities of Gli1 and Gli2 in the Absence of Ift 88 and the Primary Cilia. J Dev Biol 7.

137. Wang Y, Arvanites AC, Davidow L, Blanchard J, Lam K, Yoo JW, Coy S, Rubin LL, McMahon AP (2012), Selective identification of hedgehog pathway antagonists by direct analysis of smoothened ciliary translocation. Acs Chem Biol 7, 1040-1048.

138. Watson CJ, Khaled WT (2008), Mammary development in the embryo and adult: a journey of morphogenesis and commitment. Development 135, 995-1003.

139. Wessler S, Krisch LM, Elmer DP, Aberger F (2017), From inflammation to gastric cancer - the importance of Hedgehog/GLI signaling in Helicobacter pylori-induced chronic inflammatory and neoplastic diseases. Cell Commun Signal 15, 15.

140. Woo WM, Zhen HH, Oro AE (2012), Shh maintains dermal papilla identity and hair morphogenesis via a Noggin-Shh regulatory loop. Genes Dev 26, 1235-1246.

141. Wu F, Zhang Y, Sun B, McMahon AP, Wang Y (2017), Hedgehog Signaling: From Basic Biology to Cancer Therapy. Cell Chem Biol 24, 252-280.
142. Wu VM, Chen SC, Arkin MR, Reiter JF (2012), Small molecule inhibitors of Smoothened ciliary localization and ciliogenesis. Proc Natl Acad Sci U S A 109, 13644-13649.

143. Xiao Y, Thoresen DT, Miao L, Williams JS, Wang C, Atit RP, Wong SY, Brownell I (2016), A Cascade of Wnt, Eda, and Shh Signaling Is Essential for Touch Dome Merkel Cell Development. Plos Genet 12, e1006150.

144. Xu M, Gong A, Yang H, George SK, Jiao Z, Huang H, Jiang X, Zhang Y (2015), Sonic hedgehog-glioma associated oncogene homolog 1 signaling enhances drug resistance in CD44 (+)/Musashi-1 (+) gastric cancer stem cells. Cancer Lett 369, 124-133.

145. Yao HH, Whoriskey W, Capel B (2002), Desert Hedgehog/Patched 1 signaling specifies fetal Leydig cell fate in testis organogenesis. Genes Dev 16, 1433-1440.

146. Yao S, Lum L, Beachy P (2006), The ihog cell-surface proteins bind Hedgehog and mediate pathway activation. Cell 125, 343-357.

147. Zhang W, Kang JS, Cole F, Yi MJ, Krauss RS (2006), Cdo functions at multiple points in the Sonic Hedgehog pathway, and Cdo-deficient mice accurately model human holoprosencephaly. Dev Cell 10, 657-665.

148. Zhang XM, Ramalho-Santos M, McMahon AP (2001), Smoothened mutants reveal redundant roles for Shh and Ihh signaling including regulation of $\mathrm{L} / \mathrm{R}$ symmetry by the mouse node. Cell 106, 781-792.

149. Zhulyn O, Hui CC (2015), Sufu and Kif7 in limb patterning and development. Dev Dyn 244, 468-478.

Cite this article as: Zheng L, Rui C, Zhang H, Chen J, Jia X, \& Xiao Y (2019) Sonic hedgehog signaling in epithelial tissue development. Regen Med Res, 7, 3 